\title{
Chroococcidiorella tianjinensis gen. et sp. nov. (Trebouxiophyceae, Chlorophyta), a Green Alga Arises from the Cyanobacterium TDX16
}

\author{
Qinglin Dong*, Xiangying Xing \\ Department of Bioengineering, Hebei University of Technology, Tianjin, China \\ Email: *qldong@hebut.edu.cn
}

How to cite this paper: Dong, Q.L. and Xing, X.Y. (2020) Chroococcidiorella tianjinensis gen. et sp. nov. (Trebouxiophyceae, Chlorophyta), a Green Alga Arises from the Cyanobacterium TDX16. American Journal of Plant Sciences, 11, 1814-1826.

https://doi.org/10.4236/ajps.2020.1111130

Received: October 9, 2020

Accepted: November 27, 2020

Published: November 30, 2020

Copyright ( 2020 by author(s) and Scientific Research Publishing Inc. This work is licensed under the Creative Commons Attribution International License (CC BY 4.0).

http://creativecommons.org/licenses/by/4.0/

\begin{abstract}
All algae documented so far are of unknown origin. Here, we provide a taxonomic description of the first origin-known alga TDX16-DE that arises from the Chroococcidiopsis-like endosymbiotic cyanobacterium TDX16 by de novo organelle biogenesis after acquiring its green algal host Haematococcus pluvialis's DNA. TDX16-DE is spherical or oval, with a diameter of 2.0-3.6 $\mu \mathrm{m}$, containing typical chlorophyte pigments of chlorophyll $\mathrm{a}$, chlorophyll $\mathrm{b}$ and lutein and reproducing by autosporulation, whose $18 \mathrm{~S}$ rRNA gene sequence shows the highest similarity of $99.7 \%$ to that of Chlorella vulgaris. However, TDX16-DE is only about half the size of $C$. vulgaris and structurally similar to $C$. vulgaris only in having a chloroplast-localized pyrenoid, but differs from $C$. vulgaris in that 1) it possesses a double-membraned cytoplasmic envelope but lacks endoplasmic reticulum and Golgi apparatus; and 2) its nucleus is enclosed by two sets of envelopes (four unit membranes). Therefore, based on these characters and the cyanobacterial origin, we describe TDX16-DE as a new genus and species, Chroococcidiorella tianjinensis gen. et sp. nov., which sets the basis for multidisciplinary research.
\end{abstract}

\section{Keywords}

Green Algae, Cyanobacterial Origin, Chroococcidiorella tianjinensis, $18 \mathrm{~S}$ rRNA Gene Sequence, Ultrastructure

\section{Introduction}

Chlorella vulgaris is the first documented Chlorella green alga discovered by Beijerinck in 1890 [1]. Since then, about 1000 orbicular-shaped Chlorella and Chlorella-like green algae have been isolated [2]. Classification of these small 
coccoid chlorophytes is a difficult task, because their origins and evolutionary histories/relationships, the crucial information necessary for their accurate assignments, are unknown. In this circumstance, the Chlorella and Chlorella-like green algae are classified traditionally by comparing the degrees of resemblance of their morphological, biochemical, physiological and ultrastructural features [3]-[10] and currently by inferring their origins and evolutionary histories/relationships via phylogenetic analyses of the molecular data, e.g., sequences of the SSU and ITS regions of nuclear-encoded ribosomal DNA [11]-[23]. As such, the taxonomy of Chlorella and Chlorella-like green algae is problematic and unstable, as indicated by the frequent taxonomic revisions.

In our previous studies, we found that the endosymbiotic cyanobacterium TDX16 resembling Chroococcidiopsis thermalis [24] escaped from the senescent/necrotic cells of green alga Haematococcus pluvialis (host) [25], and turned into a Chlorella-like green alga TDX16-DE [26] by de novo organelle biogenesis after hybridizing the acquired host's DNA with its own one and expressing the hybrid genome [27]. Therefore, the Chlorella-like green alga TDX16-DE arises from the Chroococcidiopsis-like cyanobacterium TDX16, which is the first alga and also the first organism with known origin and formation process and thus of great importance and significance in biology.

The present study aims at taxonomic assignment of TDX16-DE to lay the basis for relevant research. Based upon TDX16-DE's cyanobacterial origin in combination with its cell morphology, ultrastructure, photosynthetic pigments and $18 \mathrm{~S}$ rRNA gene sequence, we describe TDX16-DE as a new genus and species, Chroococcidiorella tianjinensis gen. et sp. nov.

\section{Materials and Methods}

\subsection{Strain and Cultivation}

The green alga TDX16-DE is derived from the cyanobacterium TDX16, the formation process of which has been elucidated in our previous study [27]. The obtained TDX16-DE was inoculated into $250-\mathrm{ml}$ autoclaved flasks containing 100 $\mathrm{ml} \mathrm{BBM}$ medium [28] and cultivated in the incubator with continuous light of $60 \mu \mathrm{mol}$ photons $\mathrm{m}^{-2} \cdot \mathrm{s}^{-1}$, at $25^{\circ} \mathrm{C}$.

\subsection{Microscopy Observations}

Light microscopy: TDX16-DE cells were examined with a light microscope BK6000 (Optec, China). Photomicrographs were taken under the oil immersion objective lens $(100 \times)$ using a DV E3 630 camera.

Transmission electron microscopy: TDX16-DE cells were harvested by centrifugation (3000 rpm, $10 \mathrm{~min}$ ) and fixed overnight in $2.5 \%$ glutaraldehyde (50 $\mathrm{mM}$ phosphate buffer, $\mathrm{pH} 7.2$ ) and $1 \%$ osmium tetroxide (the same buffer) for 2 $\mathrm{h}$ at room temperature. After dehydration with ascending concentrations of ethanol, the fixed cells were embedded in Spurr's resin at $60^{\circ} \mathrm{C}$ for $24 \mathrm{~h}$. Ultrathin sections (60 to $80 \mathrm{~nm}$ ) were cut with a diamond knife, mounted on a copper 
grid, double-stained with $3 \%$ uranyl acetate and $0.1 \%$ lead citrate, and examined using a JEM1010 electron microscope (JEOL, Japan).

\subsection{Pigment Analyses}

In vivo absorption spectrum: TDX16-DE cells were scanned with an ultraviolet-visible spectrophotometer Cary 300 (Agilent, USA).

Pigment separation and identification: Chlorophyll $b(\mathrm{Chl} b)$ and lutein were separated by thin-layer chromatography according to the method described by Lichtenthaler [29]. Pigments were analyzed with the spectrophotometer Cary 300 (Agilent, USA), and identified by spectroscopic matching with the published data.

\subsection{S rRNA Gene Sequence}

DNA sample was prepared in the same way as described in our previous study [27]. 18S rRNA gene was amplified using the primers 5'-ACCTGGTTGATCCTGCCAGTAG-3' and 5'-ACCTTGTTACGACTTCTCCTTCCTC-3' [30] under the conditions: $5 \mathrm{~min}$ at $95^{\circ} \mathrm{C}, 35$ cycles of $30 \mathrm{~s}$ at $95^{\circ} \mathrm{C}, 30 \mathrm{~s}$ at $55^{\circ} \mathrm{C}$ and $1 \mathrm{~min}$ at $72^{\circ} \mathrm{C}$ and a final $10 \mathrm{~min}$ extension step at $72^{\circ} \mathrm{C}$. The amplified product was sequenced on ABI 3730 DNA analyzer (PerkinElmer Biosystems, USA).

\section{Results}

\subsection{Morphology and Ultrastructure}

TDX16-DE cells are green, spherical or oval, about 2.0-3.6 $\mu \mathrm{m}$ in diameter (young cells 2.0-2.9 $\mu \mathrm{m}$; mature cells 2.9-3.6 $\mu \mathrm{m}$ ) (Figure 1), containing one nucleus, one chloroplast, one or two mitochondria and one or several vacuoles,

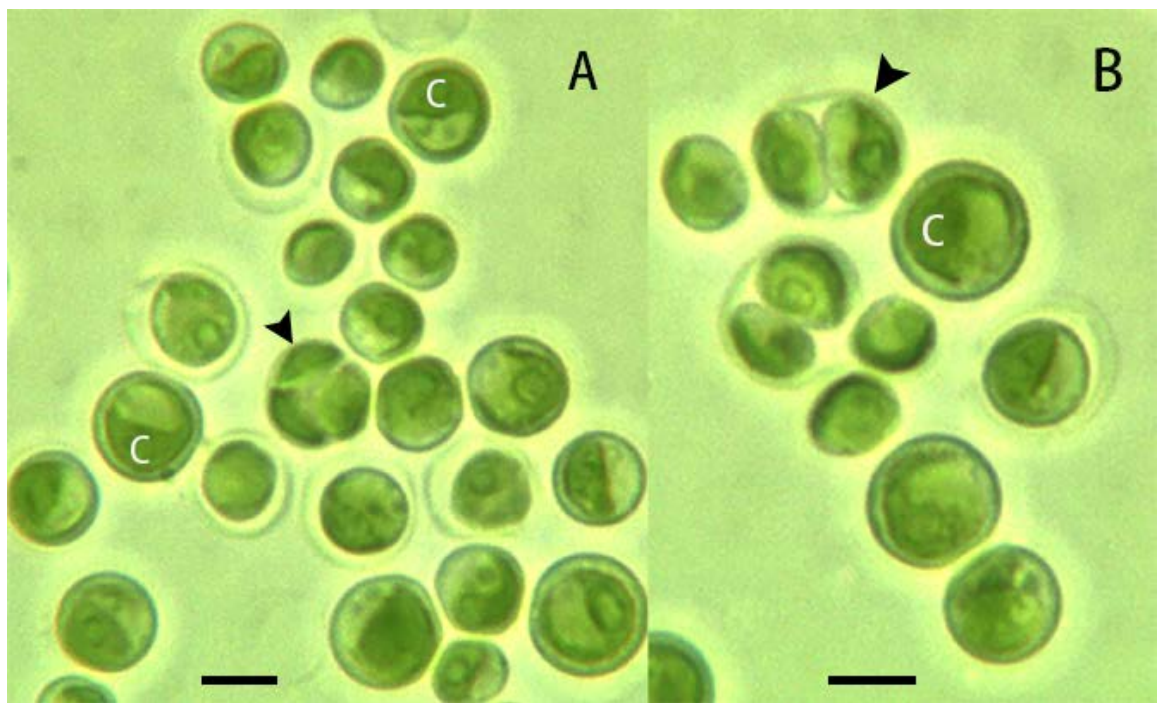

Figure 1. Morphology of Chroococcidiorella tianjinensis. (A) A three-celled autosporangium (arrowhead). (B) A two-celled autosporangium (arrowhead). C, chloroplast. Scale bars $=2 \mu \mathrm{m}$. 
but no endoplasmic reticulum, Golgi apparatus and peroxysome (Figure 2). The nucleus has two sets of envelopes, which are in close apposition in most cases (Figures 2(B)-(D)), but separated from each other when the electron-dense vesicles bud from the nuclear envelope into the interenvelope space, and migrate outside to the chloroplast envelope and cytoplasmic envelope (Figure 2(A)). The parietal chloroplast is "e"-shaped, in which there are starch granules, plastoglobules and a prominent pyrenoid that is surrounded by two starch plates and bisected by two pairs of thylakoids (Figure 2). Mitochondria lie between the chloroplast and nucleus in the chloroplast cavity (Figure 2(A), Figure 2(B), Figure 2(D)). Vacuoles are encircled by two unit membranes, sequestering electron-transparent or electron-dense materials (Figure 2(A), Figure 2(C), Figure 2(D)). The cells are enclosed with a cytoplasmic envelope (two unit membranes),

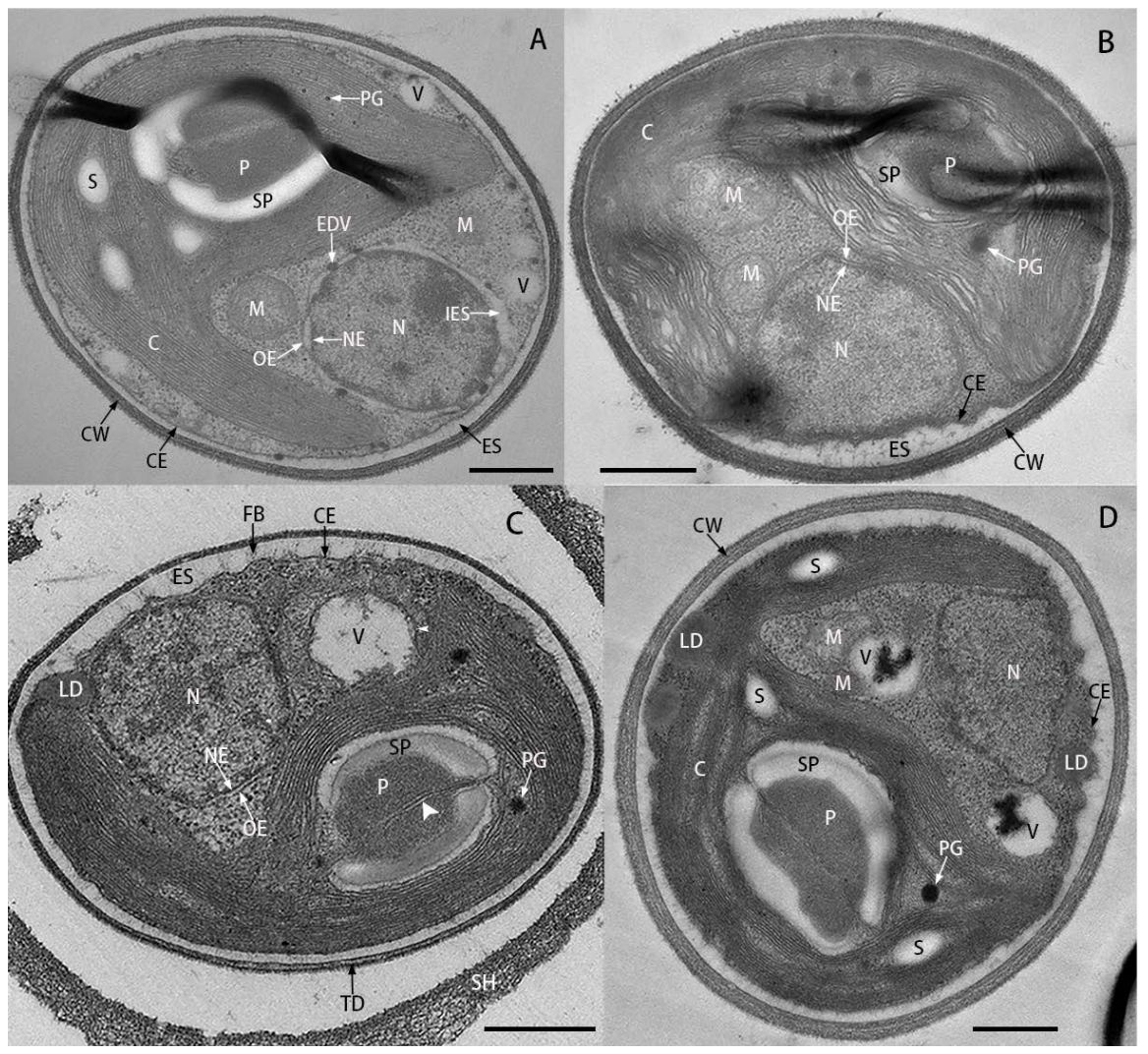

Figure 2. Ultrastructure of Chroococcidiorella tianjinensis. (A) The two sets of nuclear envelopes separate from each other, resulting in a broad interenvelope space. (B) The two sets of nuclear envelopes and cytoplasmic envelope are in close apposition. (C) The pyrenoid is bisected by two thylakoids (large arrowhead), the vacuole is delimited by double membranes (small arrowhead), the outer sheath of cell wall detaches from the trilaminar domain and microfibrils emanate from the cytoplasmic envelope. (D) Lipid droplets form on the inner leaflet of cytoplasmic envelope that consists of two membranes. C, chloroplast; CE, cytoplasmic envelope; CW, cell wall; EDV, electron-dense vesicle; ES, extracytoplasmic space; FB, microfibrils; IES, interenvelope space; LD, lipid droplet; $\mathrm{M}$, mitochondrion; N, nucleus; NE, nuclear envelope; OE, outer nuclear envelope; P, pyrenoid; PG, plastoglobule; S, starch granule; SH, sheath; SP; starch plate; TD, trilaminar domain; $\mathrm{V}$, vacuole. Scale bars $=0.5 \mu \mathrm{m}$. 
on and from which lipid droplets form and microfibrils emanate into the extracytoplasmic space respectively (Figure 2(C), Figure 2(D)), indicating that the double-membraned cytoplasmic envelope serves the functions of endoplasmic reticulum and Golgi apparatus for synthesizing lipids and building materials of cell wall. The cell wall comprises an inner stable trilaminar domain with a dark-light-dark configuration, reminiscent of the cell wall of TDX16 [27], and an outer loosely-compacted stratified sheath (Figure 2), the latter of which occasionally scales off owing to osmotic-shock during cell fixation (Figure 2(C)). It is noteworthy that the two unit membranes of cytoplasmic envelope and vacuoles, like those of chloroplast and mitochondrial envelopes, are difficult to distinguish when they are tightly appressed and easily misrecognized as the two layers of one unit membrane as they are separated, while the two sets of nuclear envelopes are easily misinterpreted as the two unit membranes of one nuclear envelope without being aware of their formation processes [27].

\subsection{Reproduction}

TDX16-DE reproduces exclusively by autosporulation with the production of two (Figure 1(B), Figure 3(B)), three (Figure 1(A), Figure 3(C)) and four (Figure 3(D)) daughter cells (autospores) per autosporangium; the autospores are liberated after apical rupture of the autosporangium (Figure 3(B)). Structurally, the autosporangium of TDX16-DE is more similar to the sporangia of TDX16 [27] and C. thermalis [24] than to the aplanosporangium of $H$. pluvialis [27]. At the beginning of autosporulation, the chloroplast splits into two small ones, while the nucleus disassembles and vanishes (Figure 3(A)). Consistently, nucleus appears only in one cell in the immature four-celled autosporangium (Figure 3(D)), but in all cells in the mature three-celled autosporangium (Figure 3(C)); by contrast chloroplasts present in each cells in both the mature and immature autosporangia (Figure 3(C), Figure 3(D)). These results suggest that chloroplasts develop by splitting the existing ones, while nuclei form de novo in the daughter cells during autosporulation.

\subsection{Photosynthetic Pigments}

In vivo absorption spectrum of TDX16-DE (Figure 4(A)) exhibits two absorption peaks of chlorophyll a ( $\mathrm{Chl}$ a) at 440 and $680 \mathrm{~nm}$, a conspicuous shoulder peak at $653 \mathrm{~nm}$ of chlorophyll b (Chl b) [31] [32], and a merged peak of carotenoids around $485 \mathrm{~nm}$. Chl b and lutein separated from TDX16-DE display absorption peaks at 456 and $645 \mathrm{~nm}$ (Figure 4(B)), 420, 446 and $475 \mathrm{~nm}$ (Figure $4(C))$ respectively, identical to those of the corresponding plant pigments [29]. Hence, TDX16-DE contains $\mathrm{Chl} \mathrm{a,} \mathrm{Chl} \mathrm{b} \mathrm{and} \mathrm{lutein.}$

\subsection{S rRNA Gene Sequence}

18S rRNA gene sequence of TDX16-DE (GenBank: MW033971.1) shows the highest similarity of $99.7 \%$ to those of $C$. vulgaris deposited in GenBank. 


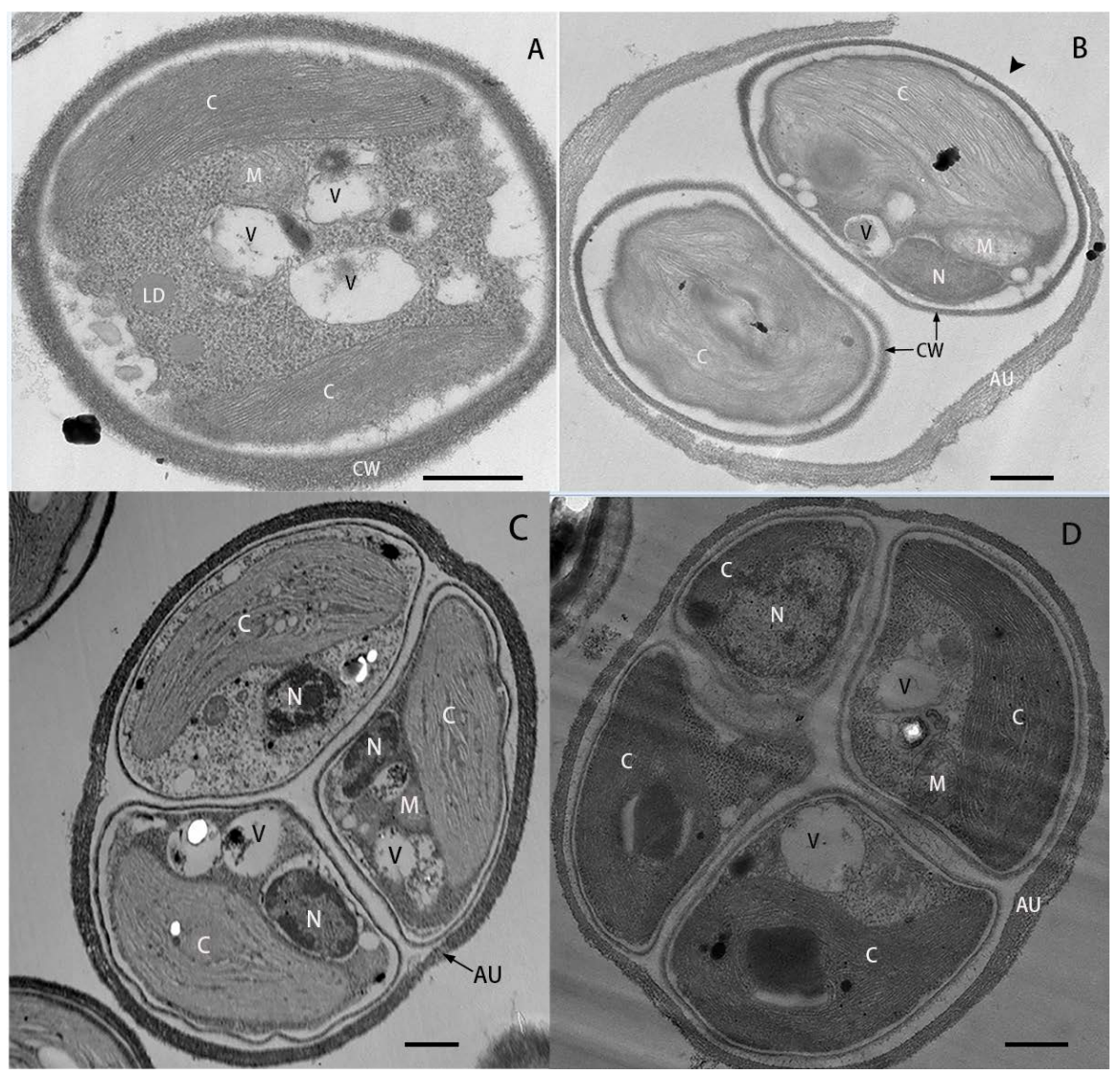

Figure 3. Reproduction of Chroococcidiorella tianjinensis. (A) A cell contains two small chloroplasts but no nucleus. (B) A two-celled autosporangium ruptures, resulting in an opening (arrowhead). (C) An autosporangium sequesters three mature daughter cells. (D) An autosporangium encloses four immature daughter cells. AU, autosporangium; C, chloroplast; CW, cell wall; LD, lipid droplet; $\mathrm{M}$, mitochondrion; $\mathrm{N}$, nucleus; $\mathrm{V}$, vacuole. Scale bars $=0.5 \mu \mathrm{m}$.

\section{Discussion}

The presence of typical chlorophyte pigments of $\mathrm{Chl}$ a, $\mathrm{Chl} \mathrm{b}$ and lutein in TDX16-DE (Figure 4) indicates that TDX16-DE belongs to the Chlorophyta, and the highest similarity of $99.7 \%$ between the $18 \mathrm{~S}$ rRNA gene sequences of TDX16-DE and C. vulgaris suggests that TDX16-DE is most similar to C. vulgaris. The results of cell morphology and ultrastructure, however, demonstrate that TDX16-DE is distinct from $C$. vulgaris, because they share only two common traits but differ in six characters. Their common features include 1) chloroplasts are embedded with starch granules and a pyrenoid that is surrounded by two starch plates and bisected by two pairs of thylakoids in TDX16-DE (Figure 2) and C. vulgaris [33] [34] [35] and 2) reproduction is achieved by autosporulation, generating two, three and four autospores in TDX16-DE (Figure 1, Figure 3 ) and $C$. vulgaris [33] [36]. By contrast, their different characters encompass 1) TDX16-DE (2.0-3.6 $\mu \mathrm{m}$ ) (Figure 1, Figure 2) is only about half the size of $C$. vulgaris $(5.0-7.0 \mu \mathrm{m})$ [35] [36]; 2) TDX16-DE's chloroplast is "e"-shaped (Figure 2 ), while the chloroplast of $C$. vulgaris is cup-shaped and sometimes has two 

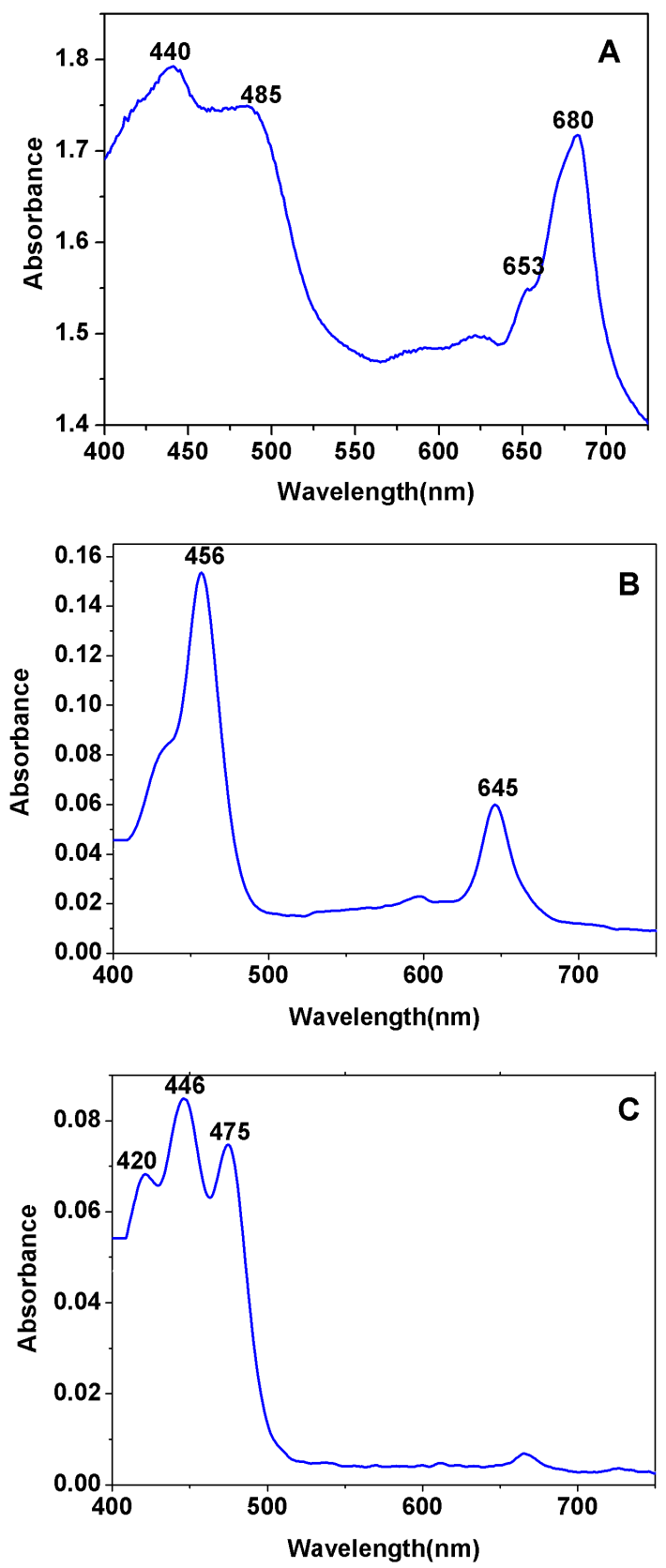

Figure 4. Photosynthetic pigments of Chroococcidiorella tianjinensis. (A) In vivo absorption spectrum. (B) Absorption spectrum of the separated Chl b. (C) Absorption spectrum of the separated lutein.

lobes (bilobed) [35] [37]; 3) TDX16-DE lacks endoplasmic reticulum and Golgi apparatus (Figure 2), while C. vulgaris possesses both of the two organelles [34] [37] [38] [39]; 4) TDX16-DE's nucleus is enclosed by two sets of envelopes (Figure 2), while the nucleus of $C$. vulgaris has one envelope [38]; 5) TDX16-DE has a double-membraned cytoplasmic envelope (Figure 2), while $C$. vulgaris has a single-membraned cytoplasmic membrane [36]; and 6) daughter cell nuclei form de novo in TDX16-DE (Figure 3), but develop by division of the existing 
one in C. vulgaris [36] [37].

Since TDX16-DE is tiny $(2.0-3.6 \mu \mathrm{m})$ and nearly pico-sized $(<3 \mu \mathrm{m})$, it is much similar in structure, particularly organelle number and arrangement, to the pico-sized Nannochloris-like green algae, which have a minimal set of organelles and differ from TDX16-DE in their absence of pyrenoid, such as Choricystis minor [40], Pseudodictyosphaerium jurisii [41], Mychonastes homosphaera [42], Picocystis salinarum [43], Picochlorum oklahomensis [44], Chloroparva pannonica [45] and Pseudochloris wilhelmii [46]. The structural similarity between TDX16-DE and these Nannochloris-like green algae lies primarily in three aspects: 1) absence of endoplasmic reticulum and Golgi apparatus (except the Golgi apparatus-like structure in $P$. salinarum, $P$. jurisii and $P$. wilhelmii); 2) the nucleus is peripherally localized in the opening of chloroplast cavity and appressed to the cytoplasmic membrane/envelope; and 3) mitochondria situate between the chloroplast and nucleus and usually attach to the chloroplast.

Phylogenetic analysis of SSU and ITS rDNA is now applied predominately for classifying the origin-unknown algae by inferring their origins and evolutionary histories/relationships, which is, however, unnecessary and also unfeasible for taxonomic assignment of TDX16-DE. Because 1) the origin and developmental relationship of TDX16-DE is clearly known; and 2) current molecular phylogenetic analyses are based on the fundamental assumption that all algae descend directly from other algae, while TDX16-DE is not the case, which arises from the cyanobacterium TDX16 by acquiring $H$. pluvialis's DNA [27]. So, TDX16-DE descend, to some extent, only indirectly from the green alga $H$. pluvialis via the cyanobacterium TDX16. Such a developmental relationship apparently cannot be inferred by current molecular phylogenetic analysis, or in other words, the inferred phylogenetic relationship does not reflect the true origin and development history of TDX16-DE (it is also the case for the common ancestor of algae that did not arise from algae).

In truth, the experimental results discussed above are sufficient for assigning TDX16-DE. The Chlorella and Chlorella-like coccoid green algae are currently categorized into two different clades within in Chlorellaceae: the Chlorella-clade and the Parachlorella-clade [13]. The highest similarity of TDX16-DE's 18S rRNA gene sequence to that of $C$. vulgaris, and the typical Chlorella structure: a prominent pyrenoid surrounded by two starch plates and bisected by two pairs of thylakoids in the single parietal chloroplast, indicate that TDX16-DE falls within the Chlorella-clade; while TDX16-DE's compartmental characters: two sets nuclear envelopes, double-membraned cytoplasmic envelope and vacuoles and absence of endoplasmic reticulum, Golgi apparatus and peroxysome, distinguish it from all the members within the genera of Chlorella-clade [2] [16] [17] [20] [23] [47]. Therefore, considering TDX16-DE's unique compartmental features and definite origin, we propose a new genus Chroococcidiorella within the Chlorella-clade and TDX16-DE is a new species Chroococcidiorella tianjinensis. 
Chroococcidiorella Q.L. Dong \& X. Y. Xing, gen. nov.

Cells solitary, spherical or oval, enclosed by a double-membraned cytoplasmic envelope. Nucleus encircled by two sets of envelopes, endoplasmic reticulum and Golgi apparatus absent. One parietal chloroplast with a pyrenoid surrounded by two starch plates and traversed by two pairs of thylakoids. Asexual reproduction by autosporulation. Sexual reproduction unknown.

Etymology: The genus Chroococcidiorella is named for its origin-Chroococcidiopsis; plus ella, small or diminutive.

Type species: Chroococcidiorella tianjinensis Q. L. Dong \& X. Y. Xing.

\section{Chroococcidiorella tianjinensis Q. L. Dong \& X. Y. Xing, sp. nov. (Figures 1-3)}

Cells solitary, spherical or oval, with a diameter of 2.0-3.6 $\mu \mathrm{m}$, One nucleus with two sets of envelopes, one parietal "e"-shaped chloroplast with a pyrenoid surrounded by two starch plates and bisected by double thylakoids, double-membraned cytoplasmic envelope and vacuoles. No endoplasmic reticulum, Golgi apparatus and peroxysome. Asexual reproduction via 2-4 autospores. Sexual reproduction not observed.

Holotype: Strain CCTCC AF2020007 $7^{\mathrm{T}}$ has been cryopreserved in China Center for type Culture Collection, Wuhan University, Wuhan, China. Also, a living culture FACHB-3081 has been deposited in the Freshwater Algae Culture Collection at the Institute of Hydrobiology, Chinese Academy of Sciences, Wuhan, China.

Etymology: The species name tianjinensis refers to the Chinese city, Tianjin, where the formation of this alga was found.

\section{Conclusion}

The taxonomic assignment of TDX16-DE as Chroococcidiorella tianjinensis sets the basis for multidisciplinary research. There is no reason to think that C. tianjinensis is the only alga (eukaryote) with cyanobacterial (prokaryotic) origin, so, C. tianjinensis along with its cyanobacterial precursor TDX16 whose genome is already available (GenBank NDGV00000000) [27] provide an unprecedented reference and platform for the study of different subjects, e.g., cellular, molecular, genomic, genetic and evolutionary biology, which holds the potential to resolve the relevant puzzles and make breakthroughs in biology.

\section{Conflicts of Interest}

The authors declare no conflicts of interest regarding the publication of this paper.

\section{References}

[1] Beijerinck, M.W. (1890) Culturversuche mit Zoochlorellen, Lichen-Engonidien und Anderen Niederen Algen I-III. Botanische Zeitung, 48, 726-740. 
[2] Luo, W., Pröschold, T., Bock, C. and Krienitz, L. (2010) Generic Concept in Chlorella-Related Coccoid Green Algae (Chlorophyta, Trebouxiophyceae). Plant Biology, 12, 545-553. https://doi.org/10.1111/j.1438-8677.2009.00221.x

[3] Fott, B. and Nováková, M. (1969) A Monograph of the Genus Chlorella. The Freshwater Species. In: Fott, B., Ed., Studies in Phycology, Academia, Praha, 10-59.

[4] Andreyeva, V.M. (1975) Rod Chlorella. Izdat. Nauka, Leningrad, 82 p.

[5] Maruyama, K. (1977) Classification of Chlorella Strains by Cell Appearance and Group Sera. The Botanical Magazine Tokyo, 90, 57-66.

https://doi.org/10.1007/BF02489469

[6] KÜmmel, H. and Kessler, E. (1980) Physiological and Biochemical Contributions to the Taxonomy of the Genus Chlorella. XIII. Serological Studies. Archives of Microbiology, 126, 15-19. https://doi.org/10.1007/BF00421886

[7] Takeda, R. (1991) Sugar Composition of the Cell Wall and the Taxonomy of Chlorella (Chlorophyceae). Journal of Phycology, 27, 224-232.

https://doi.org/10.1111/j.0022-3646.1991.00224.x

[8] Kessler, E. and Huss, V.A.R. (1992) Comparative Physiology and Biochemistry and Taxonomic Assignment of the Chlorella (Chlorophyceae) Strains of the Culture Collection of the University of Texas at Austin. Journal of Phycology, 28, 550-553. https://doi.org/10.1111/j.0022-3646.1992.00550.x

[9] Ikeda, T. and Takeda, H. (1995) Species-Specific Differences of Pyrenoids in Chlorella (Chlorophyta). Journal of Phycology, 31, 813-818.

https://doi.org/10.1111/j.0022-3646.1995.00813.x

[10] Hanagata, N., Karube, I., Chihara, M. and Silva, P.C. (1998) Reconsideration of the Taxonomy of Ellipsoidal Species of Chlorella (Trebouxiophyceae, Chlorophyta), with Establishment of Watanabea gen. nov. Phycological Research, 46, 221-229. https://doi.org/10.1111/j.1440-1835.1998.tb00117.x

[11] Friedl, T. (1995) Inferring Taxonomic Positions and Testing Genus Level Assignments in Coccoid Green Algae: A Phylogenetic Analysis of 18S Ribosomal RNA Sequences from Dictyochloropsis reticulata and from Members of the Genus Myrmecia (Chlorophyta, Trebouxiophyceae cl. nov.). Journal of Phycology, 31, 632-639. https://doi.org/10.1111/j.1529-8817.1995.tb02559.x

[12] Huss, V., Frank, C., Hartmann, E., Hirmer, M., Kloboucek, A., Seidel, B., Wenzeler, P. and Kessler, E. (1999) Biochemical Taxonomy and Molecular Phylogeny of the Genus Chlorella sensu lato (Chlorophyta). Journal of Phycology, 35, 587-598. https://doi.org/10.1046/j.1529-8817.1999.3530587.x

[13] Krienitz, L., Hegewald, E., Hepperle, D., Huss, V., Rohr, T. and Wolf, M. (2004) Phylogenetic Relationship of Chlorella and Parachlorella gen. nov. (Chlorophyta, Trebouxiophyceae). Phycologia, 43, 529-542. https://doi.org/10.2216/i0031-8884-43-5-529.1

[14] Karsten, U., Friedl, T., Schumann, R., Hoyer, K. and Lembcke, S. (2005) Mycosporing-Like Amino Acids and Phylogenies in Green Algae: Prasiola and ITS Relatives from the Trebouxiophyceae (Chlorophyta). Journal of Phycology, 41, 557-566. https://doi.org/10.1111/j.1529-8817.2005.00081.x

[15] Hoshina, R., Iwataki, M. and Imamura, N. (2010) Chlorella variabilis and Micractinium reisseri sp. nov. (Chlorellaceae, Trebouxiophyceae): Redescription of the Endosymbiotic Green Algae of Paramecium bursaria (Peniculia, Oligohymenophorea) in the 120th Year. Phycological Res., 58, 188-201.

https://doi.org/10.1111/j.1440-1835.2010.00579.x 
[16] Bock, C., Krienitz, L. and Pröschold, T. (2011) Taxonomic Reassessment of the Genus Chlorella (Trebouxiophyceae) Using Molecular Signatures (Barcodes), Including Description of Seven New Species. Fottea, 11, 293-312. https://doi.org/10.5507/fot.2011.028

[17] Pröschold, T., Darienko, T., Silva, P., Reisser, W. and Krienitz, L. (2011) The Systematic of Zoochlorella Revisited Employing an Integrative Approach. Environmental Microbiology, 13, 350-364. https://doi.org/10.1111/j.1462-2920.2010.02333.x

[18] Neustupa, J., Němcová, Y., Veselá, J., Steinová, J. and Škaloud, P. (2013) Leptochlorella corticola gen. et sp. nov. and Kalinella apyrenoidosa sp. nov.: Two Novel Chlorella-Like Green Microalgae (Trebouxiophyceae, Chlorophyta) from Subaerial Habitats. International Journal of Systematic and Evolutionary Microbiology, 63, 377-387. https://doi.org/10.1099/ijs.0.047944-0

[19] Škaloud, P., Němcová, Y., Pytela, J., Bogdanov, N.I., Bock, C. and Pickinpaugh, S.H. (2014) Planktochlorella nurekis gen. et sp. nov. (Trebouxiophyceae, Chlorophyta), a novel Coccoid Green Alga Carrying Significant Biotechnological Potential. Fottea, 14, 53-62. https://doi.org/10.5507/fot.2014.004

[20] Ma, S., Han, B., Huss, V.A.R., Hu, X., Sun, X. and Zhang, J. (2015) Chlorella thermophila (Trebouxiophyceae, Chlorophyta), a Novel Thermo-Tolerant Chlorella Species Isolated from an Occupied Rooftop Incubator. Hydrobiologia, 760, 81-89. https://doi.org/10.1007/s10750-015-2304-3

[21] Song, H., Wang, Q., Liu, X., Hu, Y., Long, J., Liu, G. and Hu, Z. (2018) Phylogenic Diversity and Taxonomic Problems of the Dictyosphaerium morphotype within the Parachlorella Clade (Chlorellaceae, Trebouxiophyceae). Journal of Eukaryotic Microbiology, 65, 382-391. https://doi.org/10.1111/jeu.12482

[22] Song, H., Liu, X., Hu, Y., Wang, Q., Long, J., Liu, G. and Hu, Z. (2018) Coronacoccus hengyangensis gen. et sp. nov., a New Member of Chlorellaceae (Trebouxiophyceae, Chlorophyta) with Radiococcacean Morphology. Phycologia, 57, 363-373. https://doi.org/10.2216/17-65.1

[23] Darienko, T., Rad-Menéndez, C., Campbell, C. and Pröschold, T. (2019) Are There Any True Marine Chlorella Species? Molecular Phylogenetic Assessment and Ecology of Marine Chlorella-Like Organisms, Including a Description of Droopiella gen. nov. Systematics and Biodiversity, 17, 811-829. https://doi.org/10.1080/14772000.2019.1690597

[24] Gonzalez-Esquer, C.R., Smarda, J., Rippka, R., Axen, S.D., Guglielmi, G., Gugger, M. and Kerfeld, C.A. (2016) Cyanobacterial Ultrastructure in Light of Genomic Sequence Data. Photosynthesis Research, 129, 147-157. https://doi.org/10.1007/s11120-016-0286-2

[25] Dong, Q.L., Li, Z.W., Xing, X.Y. and Chen, B. (2011) Discovery of an Endophytic Cyanobacterium in Haematococcus pluvialis. Journal of Hebei University of Technology, 40, 1-5. https://doi.org/10.3969/j.issn.1007-2373.2011.03.001

[26] Dong, Q.L., Xing, X.Y., Wu, H.X., Han, Y., Wei, X.L. and Zhang, S. (2016) Transition of a Prokaryotic Endosymbiotic Cyanobacterium into a Eukaryotic Green alga. Chemical Engineering (China), 44, 1-6.

https://doi.org/10.3969/j.issn.1005-9954.2016.01.001

[27] Dong, Q.L., Xing, X.Y., Han, Y., Wei, X.L. and Zhang, S. (2020) De Novo Organelle Biogenesis in the Cyanobacterium TDX16 Released from the Green Alga Haematococcus pluvialis. CellBio, 9, 29-84. https://doi.org/10.4236/cellbio.2020.91003

[28] Dong, Q.L. and Zhao, X.M. (2004) In Situ Carbon Dioxide Fixation in the Process of Natural Astaxanthin Production by a Mixed Culture of Haematococcus pluvialis 
and Phaffia rhodozyma. Catalysis Today, 98, 537-544.

https://doi.org/10.1016/j.cattod.2004.09.052

[29] Lichtenthaler, H. (1987) Chlorophylls and Carotenoids: Pigments of Photosynthetic Biomembranes. Methods in Enzymology, 148, 350-382.

https://doi.org/10.1016/0076-6879(87)48036-1

[30] Zhang, J., Huss, V.A.R., Sun, X., Chang, K. and Pang, D. (2008) Morphology and Phylogenetic Position of a Trebouxiophycean Green Alga (Chlorophyta) Growing on the Rubber Tree, Hevea brasiliensis, with the Description of a New Genus and Species. European Journal of Phycology, 43, 185-193.

https://doi.org/10.1080/09670260701718462

[31] Govindjee, and Rabinowitch, E. (1960) Two Forms of Chlorophyll a in Vivo with Distinct Photochemical Functions. Science, 132, 355-356.

https://doi.org/10.1126/science.132.3423.355

[32] Wilhelm, C., Eisenbeis, G., Wild, A. and Zahn, R. (1982) Nanochlorum eucayotum: a Very Reduced Coccoid Species of Marine Chlorophyceae. ZeitschriJt fur Natuiforschung, 37, 107-114. https://doi.org/10.1515/znc-1982-1-219

[33] Němcová, Y. and Kalina, T. (2000) Cell Wall Development, Microfibril and Pyrenoid Structure in Type Strains of Chlorella vulgaris, C kessleri, C sorokiniana Compared with C luteoviridis (Trebouxiophyceae, Chlorophyta). Algological Studies, 100, 95-105. https://doi.org/10.1127/algol_stud/100/2000/95

[34] Přibyl, P., Cepák, V. and Zachleder, V. (2013) Production of Lipids and Formation and Mobilization of Lipid Bodies in Chlorella vulgaris. Journal of Applied Phycology, 25, 545-553. https://doi.org/10.1007/s10811-012-9889-y

[35] Gärtner, G., Uzunov, B., Ingolic, E., Kofler, W., Gacheva, G., Pilarski, P., Zagorchev, L., Odjakova, M. and Stoyneva, M. (2015) Microscopic Investigations (LM, TEM and SEM) and Identification of Chlorella Isolate R-06/2 from Extreme Habitat in Bulgaria with Strong Biological Activity and Resistance to Environmental Stress Factors. Biotechnology \& Biotechnological Equipment, 29, 536-540. https://doi.org/10.1080/13102818.2015.1013283

[36] Yamamoto, M., Fujishita, M., Hirata, A. and Kawano, S. (2004) Regeneration and Maturation of Daughter Cell Walls in the Autospore-Forming Green Alga Chlorella vulgaris (Chlorophyta, Trebouxiophyceae). Journal of Plant Research, 117, 257-264. https://doi.org/10.1007/s10265-004-0154-6

[37] Bisalputra, T., Ashton, F. and Weier, T. (1966) Role of Dictyosomes in Wall Formation during Cell Division of Chlorella vulgaris. American Journal of Botany, 53, 213-216. https://doi.org/10.1002/j.1537-2197.1966.tb07324.x

[38] Griffiths, D.A. and Griffiths, D.J. (1969) The Fine Structure of Autotrophic and Heterotrophic Cells of Chlorella vulgaris (Emerson Strain). Plant Cell Physiology, 10, 11-19.

[39] Gerken, H., Donohoe, B. and Knoshaug, E. (2013) Enzymatic Cell Wall Degradation of Chlorella vulgaris and Other Microalgae for Biofuels Production. Planta, 237, 239-253. https://doi.org/10.1007/s00425-012-1765-0

[40] Krienitz, L., Huss, V. and Hümmer, C. (1996) Picoplanktonic Choricystis Species (Chlorococcales, Chlorophyta) and Problems Surrounding the Morphologically similar “Nannochloris-Like” Algae. Phycologia, 35, 332-341.

https://doi.org/10.2216/i0031-8884-35-4-332.1

[41] Krienitz, L., Takeda, H. and Hepperle, D. (1999) Ultrastructure, Cell Wall Composition, and Phylogenetic Position of Pseudodictyosphaerium jurisii (Chlorococcales, Chlorophyta) Including a Comparison with Other Picoplanktonic Green Algae. 
Phycologia, 38, 100-107. https://doi.org/10.2216/i0031-8884-38-2-100.1

[42] Hanagata, N., Malinsky-Rushansky, N. and Dubinsky, Z. (1999) Eukaryotic Picoplankton, Mychonastes homosphaera (Chlorophyceae, Chlorophyta), in Lake Kinneret, Israel. Phycological Research, 47, 263-269. https://doi.org/10.1111/j.1440-1835.1999.tb00307.x

[43] Lewin, R., Krienitz, L., Goericke, R., Takeda, H. and Hepperle, D. (2000) Picocystis salinarum gen. et sp. nov. (Chlorophyta)-A New Picoplanktonic Green Alga. Phycologia, 39, 560-565. https://doi.org/10.2216/i0031-8884-39-6-560.1

[44] Henley, W., Hironaka, J., Guillou, L., Buchheim, M., Buchheim, J., Fawley, M. and Fawley, K. (2004) Phylogenetic Analysis of the "Nannochloris-Like" Algae and Diagnoses of Picochlorum oklahomensis gen. et sp. nov. (Trebouxiophyceae, Chlorophyta). Phycologia, 43, 641-652. https://doi.org/10.2216/i0031-8884-43-6-641.1

[45] Somogyi, B., Felföldi, T., Solymosi, K., Böddi, B., Marialigeti, K. and Vörös, L. (2011) Chloroparva pannonica gen. et sp. nov. (Trebouxiophyceae, Chlorophyta)-A New Picoplanktonic Green Alga from a Turbid, Shallow Soda Pan. Phycologia, 50, 1-10. https://doi.org/10.2216/10-08.1

[46] Somogyi, B., Felföldi, T., Solymosi, K., Flieger, K., Márialigeti, K., Böddi, B. and Vörös, L. (2013) One Step Closer to Eliminating the Nomenclatural Problems of Minute Coccoid Green Algae: Pseudochloris wilhelmii, gen. et sp. nov. (Trebouxiophyceae, Chlorophyta). European Journal of Phycology, 48, 427-436. https://doi.org/10.1080/09670262.2013.854411

[47] Krienitz, L., Bock, C., Kotut, K. and Pröschold, T. (2012) Genotypic Diversity of Dictyosphaerium-morphospecies (Chlorellaceae, Trebouxiophyceae) in African Inland Waters, Including the Description of Four New Genera. Fottea, 12, 231-253. https://doi.org/10.5507/fot.2012.017 